\title{
Dificuldades de acesso a documentos inéditos: percalços em uma pesquisa de história da ciência
}

\author{
Difficulties in accessing unpublished documents: \\ misfortunes in a history of science research
}

\section{Roberto de Andrade Martins \\ Doutor em Filosofia da Ciência \\ Universidade Federal \\ de São Paulo \\ roberto.andrade.martins@gmail. com}

Recebido em: 31/12/2019

Aceito em:15/04/2020
A busca de documentos inéditos em arquivos é um dos recursos importantes utilizados pelos pesquisadores em história da ciência. Não vou me referir aqui ao caso de pesquisas sobre história das instituições, e sim de estudos que focalizam um determinado cientista (ou um pequeno grupo), para analisar suas contribuições. Através do estudo de rascunhos e outras anotações, cadernos de laboratório, fotografias, correspondência e outros materiais arquivísticos, podemos ter acesso a informações que complementam de forma extremamente significativa aquilo que foi publicado pelos pesquisadores. As motivações de um cientista, suas dúvidas, suas intenções, suas redes sociais - tudo isso pode estar oculto nos livros e artigos que publicaram, mas transparecer na análise do material encontrado em arquivos. Há condições óbvias, no entanto, para que isso seja possível: (1) a documentação inédita deve ter sido conservada; (2) deve ser possível localizar onde ela está; (3) ela deve estar acessível ao historiador; (4) deve estar em bom estado de preservação; (5) deve existir a possibilidade de citar os documentos relevantes localizados. Além disso, para facilitar o trabalho do pesquisador, é desejável (mas não necessário): (6) que existam instrumentos de busca (como inventários e bases de dados), no caso de grandes acervos; (7) que seja possível obter reproduções de documentos dos acervos. Atualmente, podemos dizer que existe também o grande sonho de todo pesquisador: (8) que os documentos tenham sido digitalizados e estejam disponíveis na Internet para uso de qualquer pessoa interessada. 
Minha experiência prática na utilização de arquivos no exterior começou de forma muito positiva. Durante um ano (1994-1995), quando estudava algumas questões relativas à história dos estudos experimentais sobre gravitação, utilizei o arquivo localizado na biblioteca central da Universidade de Cambridge. O volume de documentação era imenso, para alguns cientistas que me interessavam, como William Thomson, barão Kelvin (1824-1907); não havia dificuldades em acessar o material, existiam bons guias de cada acervo, era possível obter fotocópias ou microfilmes de qualquer material. Ou seja: condições ideais de trabalho. Outra boa experiência foi em Paris, em 2002, quando pude estudar documentação inédita sobre radioatividade tanto na Academia de Ciências quanto no Centro Alexandre Koyré. Como seria bom se sempre tudo fosse tão fácil!

Porém, mesmo nas ocasiões indicadas acima, houve dificuldades. Um cientista que me interessava bastante era William Crookes (1832-1919). Como foi uma pessoa bastante famosa, era de se supor que sua documentação tivesse sido preservada e pudesse ser acessada em algum arquivo na Inglaterra. Pouco tempo após o falecimento de Crookes, seu amigo e biógrafo Edmund d'Albe (1868-1933) teve acesso à sua correspondência e outros documentos, com um total de mais de 40.000 itens. Infelizmente, quase tudo foi perdido - correspondência, cadernos de anotações, rascunhos e outros documentos. Pouquíssima coisa foi conservada - certa quantidade de cartas que ele enviou a outros pesquisadores e que se encontram nos acervos destes; e fragmentos de outros materiais conservados na biblioteca do Science Museum, em Londres. Utilizei a palavra "fragmentos" de modo intencional. Lá estão conservadas, por exemplo, cartas escritas por Crookes que foram censuradas (não se sabe por quem) e que possuem lacunas - algumas partes foram cortadas.

Outro caso infrutífero foi minha busca da documentação de George John Romanes (1848-1894), um pesquisador britânico que atualmente é pouco conhecido. Ele foi colaborador de Charles Darwin (1809-1882) e deu importantes contribuições para a teoria da evolução (Martins, 2006). A esposa de Romanes escreveu sua biografia, na qual transcreveu um grande número de cartas completas e partes de outras. Evidentemente, ela tinha acesso a toda a documentação do marido, após seu falecimento. O que aconteceu com esse material? Não foi repassado para a Universidade de Oxford, onde ele trabalhava quando faleceu. Ninguém sabe se foi preservado, nem onde está - se é que foi conservado.

É claro que é agradável contar sucessos de nossos trabalhos de pesquisa; mas todos aprendem também com os fracassos. E por isso vou relatar agora, de forma mais detalhada, um caso bastante frustrante - minha busca de documentação sobre Leopold ("Leo") Courvoisier (1873-1955) - um astrônomo suíço, que trabalhou quase toda sua vida na Alemanha, tendo publicado muitos trabalhos com resultados contrários à teoria da relatividade.

Courvoisier e seus estudos são pouco conhecidos. Eu também nunca havia ouvido falar sobre ele até 1984. Nesse ano, pouco tempo depois de ingressar como docente no Instituto de Física da Unicamp, tive a oportunidade de ministrar uma disciplina sobre história da teoria da relatividade, em colaboração com o professor César Lattes (1924-2005). Mais conhecido por suas pesquisas a respeito de raios cósmicos e partículas subatômicas, o professor Lattes tinha grande interesse (e conhecimento) sobre a teoria da relatividade. Era um decidido anti-relativista e nutria uma especial antipatia pelo "Alberto" - esse era o modo pelo qual ele se referia a Albert Einstein (1879-1955). Admirava, pelo contrário, as contribuições de Henri Poincaré (1854-1912) e Hendrik Antoon Lorentz (1853-1928). Em meados de 1980, Lattes havia divulgado o resultado de uma série de experimentos que realizara com outros professores da Unicamp e que parecia indicar efeitos do movimento da Terra através do éter - um resultado que logo depois foi contestado por pesquisadores do Centro Brasileiro de Pesquisas Físicas (CBPF). O experimento que Lattes realizou era muito semelhante a um que havia sido realizado no século XIX por Anders Jonas Ångström (1814-1874) e que também havia dado resultados positivos - porém, o professor Lattes não tinha conhecimento desse precedente.

Tanto por causa do interesse de Lattes quanto pela minha própria motivação pessoal, fiz nessa época uma busca sistemática de pesquisas experimentais sobre a teoria da relatividade especial - abordando especialmente as tentativas de medida do movimento da Terra através do éter. Em sua maioria, elas são pouco conhecidas - as pessoas praticamente só ouvem falar de Michelson \& Morley (Martins, 2012). Procurei não apenas experimentos 
realizados antes do desenvolvimento da teoria da relatividade, mas também posteriores. Para isso, utilizei recursos existentes na época, como a bibliografia anual "Physics Abstracts", o suplemento bibliográfico "Beiblätter zu den Annalen der Physik" (ambos publicados desde o final do século XIX) e outras fontes terciárias. Foi então que encontrei as referências de alguns dos trabalhos que Courvoisier publicou na década de 1920.

No início de 1985 já dispunha de muitos artigos de Courvoisier e comecei a estudá-los. Na época, orientei o estudante Alcides José de Paula Braga na pesquisa: "Revisão histórica e crítica das bases experimentais e teóricas do princípio da relatividade restrita" (bolsa de Iniciação Científica da FAPESP, 1984-5). Como Alcides não lia alemão, expliquei para ele algumas das pesquisas de Courvoisier, que foram apresentadas no relatório para a FAPESP. O professor Lattes ficou interessado em repetir alguns dos experimentos de Courvoisier. O objetivo do prof. Lattes não era histórico - era obter evidências contrárias à teoria da relatividade. Porém, essa linha de trabalho experimental não avançou.

De 1921 até seu falecimento, em 1955, Courvoisier publicou mais de 30 trabalhos nos quais descreveu a base teórica e os resultados de sua pesquisa, utilizando uma variedade de métodos para tentar medir a velocidade da Terra através do éter. Empregando medidas astronômicas feitas não apenas por ele próprio como também por observadores de diversos observatórios de outros locais, e realizando também experimentos com instrumentos que mandou construir, Courvoisier obteve um grande conjunto de resultados que pareciam indicar efeitos de um movimento do sistema solar através do éter, com uma velocidade de aproximadamente $600 \mathrm{~km} / \mathrm{s}$ em uma direção de cerca de $75^{\circ}$ de ascensão reta e $+40^{\circ}$ de declinação. Se esses resultados estivessem corretos, eles colocariam em xeque não apenas a teoria da relatividade de Einstein, mas também a própria teoria do éter adotada por Poincaré e Lorentz, já que esta admitia o princípio da relatividade e negava a possibilidade de deteç̧ão de qualquer efeito desse tipo. Porém, as pesquisas de Couvoisier praticamente não tiveram repercussão - não foram aceitas, nem criticadas.

Meu estudo inicial de alguns dos trabalhos de Courvoisier foi em 1985. Durante cerca de dez anos não estudei mais o assunto, mas em 1995, quando estava realizando um estágio em Cambridge, encontrei por acaso mais algumas referências importantes e comecei a rever os trabalhos de Courvoisier. Em 1998, já havia analisado cuidadosamente todos os artigos publicados por ele e os poucos trabalhos que o citavam, mas não tinha muitas informações sobre o próprio Courvoisier - não sabia sequer quando ele havia nascido e morrido. Nessa época, solicitei ajuda no grupo HASTRO-L e o professor Wolfgand Dick me indicou um necrológio escrito por Richter, que continha algumas informações importantes.

Nessa altura, precisava obter informações que não apareciam nas publicações de Courvoisier:

- Qual era sua motivação?

- Quais suas conexões pessoais e profissionais?

- Pertencia ele ao grupo de alemães que se posicionou contra Einstein nas décadas de 1920 e 1930 ?

Tais questões provavelmente poderiam ser respondidas se tivesse acesso a documentos inéditos de Courvoisier, como suas cartas. Tentei obter informações sobre documentação dele que pudesse ter sido conservada no Observatório Astronômico de Babelsberg, onde ele havia trabalhado durante quase toda sua vida, mas não obtive respostas às mensagens que enviei.

Seria possível localizar parentes de Courvoisier que tivessem conservado sua documentação pessoal, como anotações e correspondência?

Nessa época (1998) a Internet já era um instrumento razoável de busca, mas não encontrei informações sobre a família dele. Comecei então a procurar na Internet pessoas da Suíça que tivessem o sobrenome Courvoisier e enviei dezenas de mensagens, perguntando se eram parentes do astrônomo. Poucas pessoas responderam. Algumas eram até atenciosas, como a compositora e pianista Sylvie Courvoisier (nascida em 1968) - mas nunca tinham ouvido falar sobre Leo Courvoisier.

Depois de muitas tentativas, recebi uma mensagem positiva, de uma pessoa muito atenciosa chamada Andrea Courvoisier. Ela tinha uma árvore genealógica de sua família, na qual aparecia Leo Courvoisier. 
O bisavô dele, Louis Courvoisier (1788-1874), foi tataravô dela. Sendo parentes distantes, ela nunca havia mantido contato com ele, nem sabia qualquer coisa sobre sua vida. Porém, ao contrário de uma árvore genealógica que só contém os antepassados da própria pessoa, a de Andrea Courvoisier continha dados sobre todos os ramos colaterais, com informações preciosas como estas ${ }^{1}$ :

Na minha árvore genealógica eu vejo que Leo Courvoisier se casou em 4.9.1924 [...] com Louise von Magdeburg (27.12.1885 - 3.6.1967). Eles tiveram dois filhos, Rosmarie (25.3.1926) e Hans Wolfgang (6.1.1929). Não sei se ainda estão vivos.

Rosmarie se casou com Dieter Ritschl (17.1.1929) no dia 18.4.1952, tiveram quatro filhos: Christian Donatus (1953), Lukas Georg (1956), Stefan Leopold (1957) e Johannes (1959).

Descobri, assim, que Leo tivera uma filha e um filho; e que a filha havia se casado com uma pessoa chamada Dieter Ritschl. Procurei então na Internet por esse nome e não encontrei resultados, porque na verdade a informação de que Andrea Courvoisier dispunha estava equivocada: seu nome era Dietrich e não Dieter. Se dispusesse do nome correto, eu o teria localizado rapidamente, pois Dietrich Ritschl (1929-2018) era um famoso professor de Teologia, de Heidelberg. Não tendo localizado Dieter Rietschl, comecei a buscar pessoas que viviam na Suíça e que tinham o sobrenome Ritschl, especialmente com os nomes Christian Donatus, Lukas Georg, Stefan Leopold e Johannes, perguntando se eram parentes de Leo Courvoisier.

Novamente, poucas pessoas respondiam. Uma das mensagens que enviei, para um certo Johannes Ritschl, foi respondida por outra pessoa (talvez sua esposa), que me informou que ele estava escalando uma montanha, mas que em breve veria minha mensagem. De fato, depois de poucos dias ele me escreveu. Era um dos netos de Leopold Courvoisier e me informou que sua mãe (a filha de Leo) estava viva e morava na Basiléia (Basel).

Sim, eu sou o Johannes Ritschl que você está procurando. Minha mãe Rosemarie ainda está viva e nós podemos lhe dar muitas informações sobre a vida e a obra de Leo, se você quiser. Temos muitas imagens e dados que podem ser de interesse para seu trabalho de pesquisa. $^{2}$

Consegui então o contato de Rosemarie e troquei mensagens com ela. Minha impressão subjetiva inicial foi a de que ela ficou desconfiada com o contato - talvez imaginando que eu quisesse publicar uma crítica ao trabalho de seu pai. Apesar disso, concordou em conversarmos pessoalmente.

No primeiro semestre de 1999 completei uma primeira versão do meu estudo sobre Courvoisier - ainda sem informações pessoais relevantes - e apresentei o trabalho em um congresso sobre história da astronomia na universidade de Notre Dame. Em agosto do mesmo ano participei de um congresso sobre filosofia da ciência na Polônia e de outro sobre história da ciência na Itália. Entre os dois, consegui viajar para a Suíça para conversar com a filha de Courvoisier, em Basel.

Fui bem recebido por Rosemarie e seu marido Dietrich Rietschl. Obtive muitas informações importantes ${ }^{3}$; porém, ao mesmo tempo, soube que seria impossível obter documentação antiga de Leo Courvoisier, como ficará claro mais adiante.

A partir da conversa com Rosemarie e Dietrich, foi possível completar uma visão biográfica sobre Courvoisier e obter informações específicas sobre pontos relacionados com minhas questões de pesquisa. Ficou claro que nunca houve uma inimizade entre Leopold e Einstein: eles se encontraram na década de

Comunicação pessoal de Andrea Courvoisier - mensagem de 20 de abril de 1999.

Comunicação pessoal de Johannes Ritschl. Mensagem de 23 de abril de 1999.

Entrevista realizada no dia 31 de agosto de 1999. Todas as informações e citações por parte do casal foram obtidas nessa entrevista, que foi gravada em fita magnética. 
1920 e conversaram sobre as observações e experimentos que Courvoisier havia realizado; mas Einstein não admitiu que eles pudessem estar corretos. Nenhum deles conseguiu convencer o outro. Tiveram uma troca de cartas durante algum tempo - mas elas ainda não foram publicadas. Revendo, depois, os trabalhos publicados por Courvoisier, notei que ele nunca fez críticas diretas a Einstein e à teoria da relatividade - ou seja, suas pesquisas não eram um ataque pessoal nem uma tentativa de diminuir a sua contribuição.

De acordo com as informações que Rosemarie e Dietrich forneceram, Courvoisier era bastante isolado, não se aproximou de outros pesquisadores que também haviam obtido resultados experimentais contra a teoria da relatividade no mesmo período, como Dayton Miller (1866-1941) e Ernest Esclangon (1876-1954). Essa falta de contato é curiosa, porque o astrônomo francês Esclangon obteve resultados semelhantes aos de Courvoisier, em experimentos com espelhos e com medidas de gravidade. Durante cerca de 10 anos, Courvoisier teve um colaborador mais jovem em suas pesquisas - Nikolaus Benjamin Richter (1910-1980), que escreveu seu necrológio - mas este não publicou trabalhos sobre o assunto.

Leo publicou 25 artigos de suas pesquisas sobre o éter, até sua aposentadoria do Observatório de Babelsberg, em 1938. De acordo com a filha e o genro, ele nunca teve problemas no Observatório por causa de suas pesquisas: "Ele era um pesquisador puro, ele tinha liberdade". Não tinha medo de reações e não sofreu interferências negativas por seus resultados. Seus colegas nunca o atacaram.

Outra informação importante: Courvoisier se opunha fortemente ao Partido Nacional-Socialista de Hitler. Manteve sempre sua cidadania suíça, por isso não precisava se envolver com nenhum partido. Foi provavelmente por razões políticas que ele não assinou o documento liderado pelo prêmio Nobel de física Phillip Lenard (1862-1947) - um nazista - contra Einstein.

Em 1943, durante a Guerra, como Courvoisier era um cidadão suíço, ele teve autorização para passar as férias na Suíça. Toda a família viajou com ele, e não voltaram para a Alemanha. Quando a II Guerra Mundial terminou, pretendiam regressar, porém o Observatório e a residência deles agora faziam parte de Berlim Oriental - o lado controlado pela antiga União Soviética. Não retornaram e, durante muitos anos, não souberam nada sobre a casa nem sobre o Observatório. Posteriormente, tiveram notícias de que todos os instrumentos haviam sido levados para Odessa. A casa foi ocupada e todos os objetos da família foram perdidos. Toda a antiga documentação de Leo Courvoisier também desapareceu - seja aquilo que estava no Observatório, seja o que ele havia levado para sua residência. Assim sendo, não havia nenhuma possibilidade de ter acesso à sua correspondência e outros documentos do período antigo. Perguntei sobre documentos dele posteriores à mudança para a Suíça. Disseram que pouca coisa havia sido conservada. Não me mostraram nada.

O casal Rietschl relatou alguns aspectos comoventes da velhice de Leopold Courvoisier. Devido à fuga para a Suíça, ele parou de receber sua aposentadoria. Mesmo depois do final da Guerra, a Alemanha Oriental não lhe enviou nenhum pagamento. A família sobreviveu com o pagamento de um seguro social da Suíça, de 300 francos - cujo poder aquisitivo, na época, correspondia a 700 dólares atuais. Depois de alguns anos, Courvoisier começou a receber um pagamento de 100 francos por mês para trabalhar como editor das obras astronômicas de Euler. Apenas dez anos depois da fuga, a Alemanha Ocidental (e não a Oriental) começou a pagar sua pensão.

No final de sua vida, Courvoisier ainda escrevia trabalhos a respeito dos efeitos do éter. De 1946 a 1954, publicou sete artigos sobre o assunto, apresentando novas evidências do movimento do sistema solar através do éter. Em 1957 saiu o seu último artigo - uma publicação póstuma. No entanto, aparentemente, ele já não tinha esperança de convencer ninguém. Segundo sua filha Rosemarie, "Nos anos quarenta e cinquenta, quando eu era jovem, lembro-me de que meu pai falava sobre o assunto ocasionalmente, mas... não havia nenhuma possibilidade de ir contra Einstein... e ele aceitava isso". "Ele não ficava com raiva por causa disso, apenas ficava triste."

Durante o encontro com Rosemarie e seu marido, em 1999, pedi que me enviassem cópias de fotografias de Leo Courvoisier e outros materiais que ainda existissem. Depois de alguns meses, recebi apenas uma carta 
com fotocópias de algumas fotos; senti certa falta de confiança. Assim, realmente não tive acesso a nenhum documento inédito de Courvoisier.

Leopold se dedicou muito à sua pesquisa, durante décadas, publicando seus dados e conclusões a favor da existência do éter. Aparentemente, ele esperava obter alguma reação positiva de outros cientistas, mas nunca se esforçou de modo mais agressivo para divulgar seus resultados e convencer outras pessoas sobre a importância de seu trabalho. Parece ter mantido um perfil científico tímido, modesto e isolado, não procurando se associar a outros pesquisadores que também haviam obtido resultados semelhantes - não tinha um grupo social que o apoiasse.

Trabalhei de forma esporádica nessa pesquisa em 2006 e 2009, quando completei o texto do artigo. Como não havia obtido nenhuma fotografia de Courvoisier para ilustrar meu trabalho, encomendei um retrato do astrônomo ao artista Alexander Perandin Moreira. Este se baseou em uma pequena foto que lhe forneci, que havia sido publicada no início do século XX em um anuário da sociedade alemã de astrônomos. O retrato foi aprovado pela filha e pelo genro. O meu artigo foi publicado pouco tempo depois (Martins, 2011).

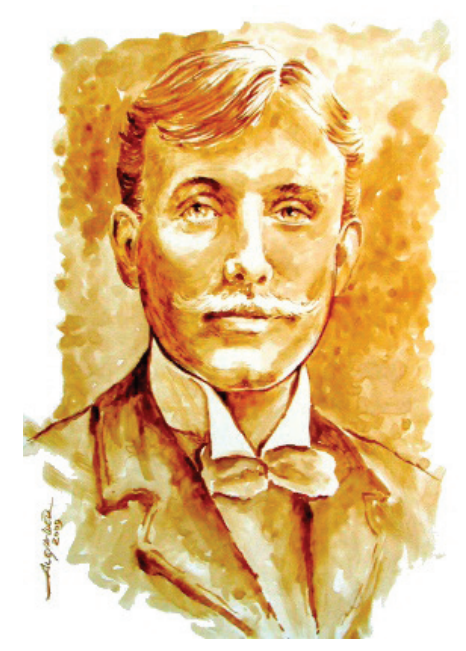

Leopold Courvoisier, pelo artista Alexander Perandin Moreira (novembro de 2009)

Por tudo o que relatei, pode-se perceber que a impossibilidade de acessar documentos inéditos de Leopold Courvoisier se deu a dois motivos. Em primeiro lugar, a documentação antiga (antes de sua fuga para a Suíça) não foi conservada por causa da guerra e separação de Berlim Oriental, ocupação da residência do astrônomo e do Observatório, com descarte de todo o material. Depois da mudança da família para a Suíça, ele continuou a publicar artigos sobre o mesmo assunto e talvez houvesse algum conjunto de cartas e rascunhos que pudesse ser útil. Porém, os seus descendentes parecem não ter se preocupado em conservar esse material e não me deram acesso ao pouco que disseram ter sido preservado. Talvez continuassem achando que eu queria escrever algo que divulgasse uma imagem negativa de Leopold.

A falta de acesso à documentação inédita prejudica o trabalho do historiador. É lamentável que um enorme volume de documentos seja perdido continuamente; e pior ainda é a existência de documentos que ficam inacessíveis, sem nenhuma justificativa válida, como no caso de Leopold Courvoisier. De qualquer forma, cumpre ao historiador da ciência o máximo de esforço para obter acesso à documentação necessária, não havendo justificativas para uma desistência prematura. 


\section{Referências}

MARTINS, Roberto de Andrade. George John Romanes e a teoria da seleção fisiológica. Episteme. Porto Alegre, v. 11, n. 24, p. 197-208, 2006.

MARTINS, Roberto de Andrade. Searching for the ether: Leopold Courvoisier's attempts to measure the absolute velocity of the solar system. Dio: International Journal of Scientific History. Baltimore, v. 17, p. 3-33, 2011.

MARTINS, Roberto de Andrade. O éter e a óptica dos corpos em movimento: a teoria de Fresnel e as tentativas de detecção do movimento da Terra, antes dos experimentos de Michelson e Morley (1818-1880). Caderno Brasileiro de Ensino de Física. Florianópolis, v. 29, n. 1, p. 52-80, 2012. 